This is an electronic reprint of the original article. This reprint may differ from the original in pagination and typographic detail.

Author(s): Laakkonen, Ilona

Title: Doing what we teach : promoting digital literacies for professional development through personal learning environments and participation

Year: $\quad 2015$

Version:

Please cite the original version:

Laakkonen, I. (2015). Doing what we teach : promoting digital literacies for professional development through personal learning environments and participation. In J. Jalkanen, E. Jokinen, \& P. Taalas (Eds.), Voices of pedagogical development : expanding, enhancing and exploring higher education language learning (pp. 171195). Research-publishing.net. https://doi.org/10.14705/rpnet.2015.000292

All material supplied via JYX is protected by copyright and other intellectual property rights, and duplication or sale of all or part of any of the repository collections is not permitted, except that material may be duplicated by you for your research use or educational purposes in electronic or print form. You must obtain permission for any other use. Electronic or print copies may not be offered, whether for sale or otherwise to anyone who is not an authorised user. 


\title{
Doing what we teach: promoting digital literacies for professional development through personal learning environments and participation
}

\author{
Ilona Laakkonen ${ }^{1}$
}

\section{Abstract}

$\mathrm{D}$ espite the proliferation of social media, few learners make effective use of digital technology to support their learning or graduate with the skills necessary for developing and communicating their expertise in the knowledge-driven networked society of the digital age. This article makes use of the concept of Personal Learning Environments (PLE) to approach the question of how digital literacies for learning can be taught and learned in the context of higher education. It presents a model of a PLE course, the overall goal of which was to equip the learners with the skills and competences needed to create their own digital environments that would enable them to tap the online networks and resources relevant for their professional and personal lives. From the viewpoint of Design-Based Research (DBR), the article lays out the design principles, pedagogical choices and activities on the course, and explains how these contributed to the creation of a learning culture. Furthermore, the design and its outcomes are reflected upon in the light of student feedback and reactions. The article argues that through the personalised, dialogic and networked approach inherent in PLE ideology, students with diverse goals, backgrounds and skills can explore practices and learn digital literacies that help them progress toward their professional goals.

Keywords: digital literacies, PLE, DBR, participatory culture, pedagogical design.

1. University services, University of Jyväskylä, Finland; ilona.laakkonen@jyu.fi

How to cite this chapter: Laakkonen, I. (2015). Doing what we teach: promoting digital literacies for professional development through personal learning environments and participation. In J. Jalkanen, E. Jokinen, \& P. Taalas (Eds), Voices of pedagogical development - Expanding, enhancing and exploring higher education language learning (pp. 171-195). Dublin: Research-publishing. net. doi:10.14705/rpnet.2015.000292 


\section{Introduction}

Providing students with the skills and knowledge they need for their future professional lives is and has always been the core task of higher education. The work increasingly relies on knowledge-driven practices and production, as work problems are becoming complex and require continuous updating of expertise and building of new knowledge, and many workplaces model themselves as highly networked and distributed environments (Littlejohn, Beetham \& McGill 2012). Being a professional in this networked field of work requires capabilities for lifelong learning, managing distributed expertise and learning across sites (Ludvigsen, Lund, Rasmussen \& Säljö 2011), participation (Jenkins et al. 2005) and effective communication in environments mediated by technology. These skills and competences have been mapped out in several models and classifications, under such titles as 21 st-century skills (e.g. ATC21S 2 ), digital or new literacies (e.g. Beetham \& Sharpe 2010; Lankshear \& Knobel 2007) and participatory culture (Jenkins et al. 2005). Because the development in the ways information is distributed and produced is a relatively recent and rapid phenomenon, formal education is faced with the challenge of developing pedagogies that would serve the various needs of students today and help them in developing the skills, literacies and identities they need in their future as professionals.

This article approaches digital literacies for learning through the concept of the Personal Learning Environment (PLE). This concept was used as both a practice-oriented description of the digital environments students use and may use for learning purposes (see e.g. Drexler 2010; Guth 2009), and as an ideological concept that entails and presumes certain pedagogical choices (see Attwell 2007). These choices involve ideas such as student involvement in the design of learning, building a learning community or affinity space (Gee 2007) in which people gather around a common interest and which allows for various levels of participation, expertise and involvement. They also include premises inherent to the idea of connectivism (Siemens 2005) and the presumption that

2. Assessment and teaching of 21 st century skills. http://atc21s.org/ 
learning these skills should happen in relation to students' identity building and wider personal goals. The question in the focus of this article is how the skills needed for professional learning and communication in digital environments can be taught and learned in the context of higher education. The article builds around a teaching experiment that took the form of an elective course provided as part of the offering of language and communication studies at the University of Jyväskylä Language Centre. It was designed for a group of Finnish university students with diverse backgrounds, stages of studies, technological skills and attitudes toward social networks.

The research presented in this article builds on a body of work conducted in a larger research and development project, Future space for shared and personal learning and working (F-SHAPE), of which the context, research strategy and methods are introduced in section 2. Design-Based Research (DBR), which seeks to contribute to the theory of learning through a practice-oriented, iterative and holistic approach, was used as a general research strategy for the project and had implications on the design and outcomes of the study at hand. The theoretical background for the teaching experiment and the concept of PLE are presented in section 3. Sections 4 and 5 present and discuss findings from the study. Section 4 presents the teacher perspective by outlining the design principles of the experiment and describing the course participants as well as the working modes of the course. Section 5, in turn, extracts the viewpoint of the students through qualitative content analysis of the students' reflections on their own learning and the pedagogical choices made by the researcher-teachers. Finally, section 6 concludes the article and provides some implications of the research.

\section{The research design}

\subsection{The research context}

The research reported in this article was initiated as part of the F-SHAPE project (2010-2012). The overall goal of the project was to develop and research 
flexible learning solutions to fit the needs of adult learners and working life. The project was funded by Tekes (the Finnish Funding Agency for Innovation) and combined research teams from two universities with business partners to explore the possibilities of and interplay between various spaces for learning: social media applications, 3D virtual environments, personal and collaborative learning environments, and informal and formal learning contexts. The PLE perspective was employed as an alternative to traditional approaches to the organisation of learning: the aim was to develop solutions that would center around the individual needs of the learner, yet still support networked and community-based learning and goals of the organisation.

The part of the project reported in the article at hand was conducted at the University of Jyväskylä Language Centre, where researchers collaborated with teachers in ethnographic and experimental modes. In Finnish higher education, language and communication courses are compulsory in all degree programmes. In addition, the University of Jyväskylä Language Centre offers a range of elective courses in various languages and modes of communication. The institution has a tradition of pedagogical development and of nourishing a culture of inquiry and renewal. Goals such as multiliteracy, ICT skills and transferable, lifelong, independent learning skills are cited as focal points in the teaching. To help its students, drawn from various academic backgrounds, become effective and convincing communicators in their specific professional fields, the Language Centre applies multimodal pedagogy, which, as mentioned by Laakkonen (2011: 20), "links meaningful communication to real-life situations, supports individual and peer processes, and encourages creativity and self-regulation". This pedagogical approach, the general teaching goals,and the organisational culture were seen as supportive of the PLE experiments.

The experiment presented in this article was designed by two researchers with backgrounds in pedagogy, ICT, linguistics and communication studies. The experiment was based on observations at the Language Centre and earlier experiments with PLEs (see section 2.2) that had called the researchers' attention to the potential of PLEs and the constraints of its implementation (see Laakkonen \& Taalas 2015). 


\subsection{Design-based research as an iterative approach}

DBR was employed as a general research strategy in the project. It "involves a goal-oriented, pragmatic and iterative view of research and proposes [means] for developing learning practices through empirical research" (Laakkonen 2011: 19, see also Reinking \& Bradley 2007). DBR mediates a dialogue between research, theory and practice by its dual objectives: it aims at responding to local needs through developing new practices and environments, yet strives to increase the general understanding of learning (Barab \& Squire 2004).

DBR is not a method as such, but employs a wide array of mixed methods and approaches. In practice, the research often takes an ethnographic form, because it fits well with an ecological view of learning. This research project was partly autoethnographic due to the close interaction with the setting and the learning position taken by the teacher-designers, who reflected throughout on their pedagogical choices. DBR usually involves a collection of an extensive body of data through multiple means of inquiry, including interviews, observation, artefacts, classroom recordings and field notes, among other methods. During its three-year duration, the F-SHAPE project involved gathering data in various contexts and by various means: the PLE tools developed for and in workshops organised for participants at an ICT conference, and for university students and staff over the span of the project; an ethnographic study on the possibilities for implementing PLEs at the Language Centre; and theoretical and practical conceptualisations of PLEs by the researchers. All of this work formed the basis for the design of the course that this article focuses on and which has been reported on in Laakkonen (2011), Laakkonen and Taalas (2015) and Juntunen and Laakkonen (2014, in Finnish).

\subsection{The research questions, data and analysis}

This article presents a sub-study that addressed the question of how digital literacies useful in the professional lives of the students today can be taught and learned. In other words, the focus is on finding the pedagogical qualities 
that help to cater for a group of learners with various backgrounds, attitudes and experiences as learners, experts and internet users. The research approach is qualitative. The answers to the research questions were sought by designing and conducting a teaching experiment - or more precisely, providing organically developing conditions for learning - in the form of an elective communication course, and then pinpointing the pedagogical choices in the course design (section 4) and evaluating the student reactions (section 5). The course was organised at the University of Jyväskylä Language Centre in the spring of 2012.

The course design is a lens for the research (Joseph 2004) and helps to target questions that are relevant to the implementation of the design itself. The course was designed and taught by two researchers, the author of this article and her colleague, both of whom have a research focus on PLEs. The researcher-teachers' notes, observations and materials served as a resource for connecting the pedagogical ideas and theories with their implementation on the course.

The student data (see Table 1) were gathered in course enrolment, during the course and shortly after the final session. They provide insights into the student perspective, including their reactions to the course design and culture and reflections on their personal learning experience.

Defining a certain starting point for the analysis would be illusory, because in practice, the dialogic and co-design principles of the course already entail continual cycles of analysis, adjustment, response and re-modification, and, furthermore, because the research approach in general implies dialogue between theory and practice. Keeping this in mind, the transcript of the final course meeting can be defined as the starting point of analysis in this article, because it contained presentations of student projects (their PLEs), their reflections on their learning journeys, feedback on the course in general and a possibility to observe group interaction and conversational patterns. These data were supported with the final assignment, a written self-reflection by the students on their learning and on the course in general. 
In the first round of analysis, the data were arranged around the themes outlined in the research questions. Excerpts concerning two themes were systematically selected: what the students considered they had learned during the course and what aspects of the pedagogical design had contributed to this learning. The following round of analysis then allowed for typing within the themes. Although each student had a unique approach to the questions, certain topics and themes evoked similar responses.

Table 1. Types of student data gathered on the course

\begin{tabular}{|c|c|c|c|c|c|}
\hline & $\begin{array}{l}\text { Type } \\
\text { of data }\end{array}$ & Data & Time & $\begin{array}{l}\text { In focus } \\
\text { of analysis }\end{array}$ & $\begin{array}{l}\text { Background/ } \\
\text { triangulation }\end{array}$ \\
\hline \multirow[t]{4}{*}{$\begin{array}{l}\text { Learning } \\
\text { outcomes }\end{array}$} & Observed & $\begin{array}{l}\text { Activity on the } \\
\text { course, activity } \\
\text { in social media, } \\
\text { questions, } \\
\text { interaction, } \\
\text { assignments, } \\
\text { course retention }\end{array}$ & $\begin{array}{l}\text { During the } \\
\text { course }\end{array}$ & $(\mathrm{X})$ & $X$ \\
\hline & Reported & $\begin{array}{l}\text { Transcript of } \\
\text { the final session } \\
\text { ( } 6 \text { students), } \\
\text { reflection paper }\end{array}$ & $\begin{array}{l}\text { At the } \\
\text { end/after } \\
\text { the course }\end{array}$ & $x$ & \\
\hline & Reported & $\begin{array}{l}\text { Questionnaire } \\
\text { upon enrolment: } \\
\text { characteristics as } \\
\text { a digital learner, } \\
\text { expectations }\end{array}$ & $\begin{array}{l}\text { Before the } \\
\text { course }\end{array}$ & & $x$ \\
\hline & $\begin{array}{l}\text { Other } \\
\text { evidence }\end{array}$ & $\begin{array}{l}\text { Reported } \\
\text { transformations } \\
\text { and changes } \\
\text { in behaviour, } \\
\text { newspaper } \\
\text { articles of two } \\
\text { students }\end{array}$ & $\begin{array}{l}\text { During/ } \\
\text { after the } \\
\text { course }\end{array}$ & & $x$ \\
\hline \multirow[t]{2}{*}{$\begin{array}{l}\text { Student } \\
\text { reactions to } \\
\text { the course } \\
\text { pedagogy } \\
\& \text { culture }\end{array}$} & Observed & $\begin{array}{l}\text { Participation } \\
\text { F2F \& online, } \\
\text { interaction, } \\
\text { assignments }\end{array}$ & $\begin{array}{l}\text { During the } \\
\text { course }\end{array}$ & & $x$ \\
\hline & Reported & $\begin{array}{l}\text { Final session } \\
\text { (6 students), } \\
\text { reflection paper }\end{array}$ & $\begin{array}{l}\text { During/ } \\
\text { after the } \\
\text { course }\end{array}$ & $x$ & \\
\hline
\end{tabular}


The citations selected for this article are more than comments of individual students. They represent the typical responses to the pedagogical choices and learning design as shared by the students in general, or they illustrate the range of approaches reported by students. The qualitative analysis is thus used to produce a representative image of the student reflections. The data excerpts provided in section 5 come from the six students who were present at the final session, and the students are referred to with pseudonyms in order maintain their privacy.

\section{Background: personal learning goals in connected environments}

\subsection{Personal learning environments and networks}

The concept of the PLE is prominently used to describe the collections of (digital) tools and environments that individual learners use, whether in formal or informal contexts, to promote their learning. The idea that it is the learners who should focus on designing their own learning environments challenges the tradition according to which Learning Management Systems (LMS) or Virtual Learning Environments (VLE) have been designed. The latter environments, typically owned and controlled by the teacher, usually centre on a specific course in a particular context, with the main focus on the management and administration of learning, not on learning itself. A PLE arranges itself around an individual student, who selects the tools and practices that best suit their needs and preferences, and in which both the ownership and control belong to the learner (see van Harmelen 2008).

In the e-learning community, the concept of PLE emerged soon after the proliferation of Web 2.0. Its conceptualisation, theorisation and implementation were motivated by the potential of social media for both personal and social aspects of learning, and as its transformative impact on knowledge and communication practices began to emerge. Sykes, Ozkoz and Thorne (2008) see that the culture and practices of Web 2.0 changes the positions of learners from consumers to producers and creators, and their role in the educational community towards co- 
builders and contributors. Downes (2007) formulates that the values of Web 2.0 and the idea of the PLE are essentially the same, namely "the fostering of social networks and communities, the emphasis on creation rather than consumption, and the decentralisation of content and control" (Downes 2007: 19).

Despite its vague definition and the rapid increase (and subsequent decline) in its popularity in the e-learning domain, PLE is more than a buzzword. It provides a useful lens for understanding what learner-centred educational design can be and how learning processes can be supported by technology (Attwell 2007). Thus, PLE in this study is first and foremost a concept that establishes certain premises and principles for how learning and teaching should be organised. The PLE is usually linked with sociocultural, constructivist and connectivist theories of learning. Connectivism, as proposed by Siemens (2005), has not been widely accepted as a learning theory, but it provides some significant insights into learning in networks. The principles of connectivism lie on the process of connecting information sources (including non-human appliances) from a variety of opinions and views, and learning and acquiring the skills and connections that help to maintain learning are more important than knowledge. Furthermore, connectivism emphasises the ability to perceive connections between ideas and concepts as a core skill, and it sees decision-making in choosing what to learn as a mode of learning within the shifting reality. These principles are also prerequisites for learners' ability to use, maintain and develop their PLEs and networks.

The model presented in Figure 1 is the result of iterative development and continuous interplay between the theory and practice of PLE in the F-SHAPE project. The model has been used in various presentations during the project and has undergone several changes and adaptations as the understanding has evolved. The model breaks the concept of PLE into its constituent parts and explicates what the personal, learning and environment components mean in relation to the learning process.

The model has a fourth component, the network, because this is in essence one of the most powerful possibilities of learning on the internet. The PLE is often 
used interchangeably or complemented with the concept of personal learning networks, that is, organic structures arranged around a learner and comprised of a practically infinite number of people the learner has access to through contacts or through internet communities and the media. The model therefore encompasses both the personal and networked aspects of digital learning.

Figure 1. Components of the PLE model

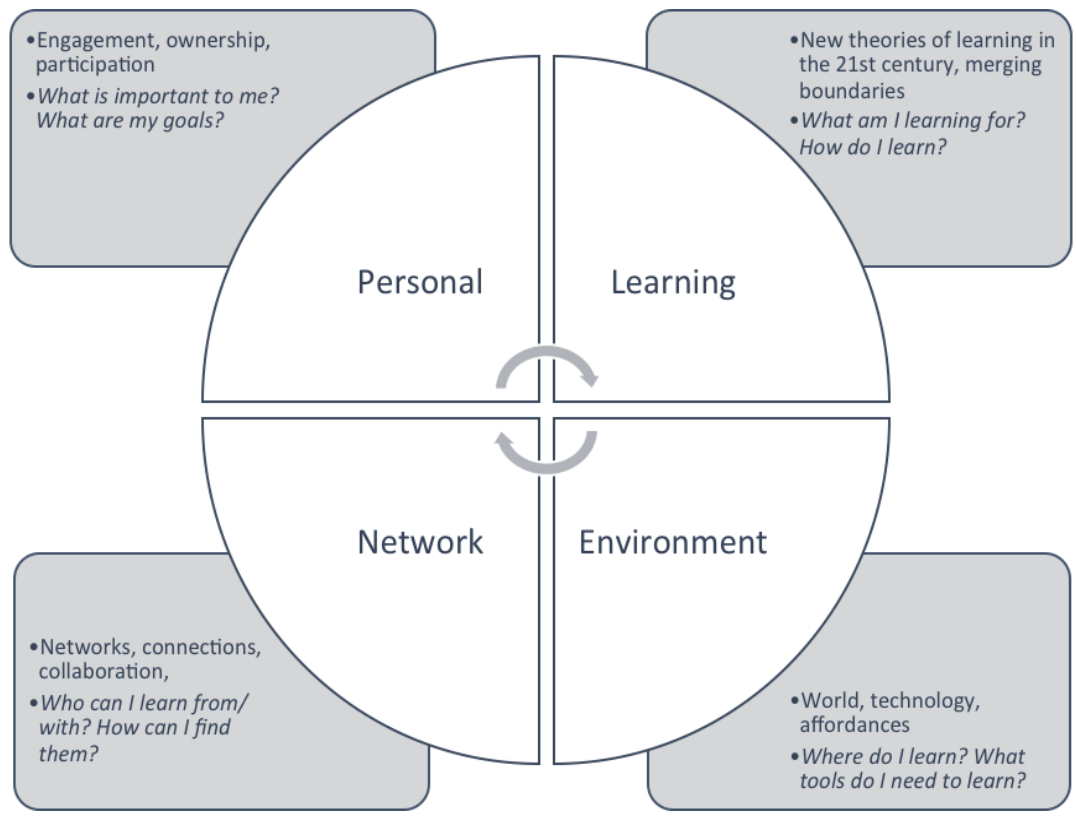

\subsection{Digital literacies as skill needed for PLE}

Jenkins et al. (2005) emphasise the participatory aspects of digital literacies, which encompass the personal, technological, social and intellectual skills that are needed to live, participate and be involved in the digitally networked world of today. As digital technology becomes increasingly central for full participation in society and the media use shifts from consumption to production and new possibilities for participation emerge, the significance of competences and 
skills related to social and personal aspects of digital use expand. At the same time, digital literacy encompasses many practical competences related to selfexpression, professional and personal learning and working in the knowledge economy.

Being able to build and maintain one's PLE requires various skills in the use of ICT environments, in regulating one's learning process, and in knowledge of the culture and practices of social networks. These capabilities, presented in Figure 1 above, are similar to the areas defined in the digital literacies for learning development framework (Beetham \& Sharpe 2010). The digital literacies development framework distinguishes three areas of capabilities relevant to digital literacy: ICT capabilities are related to the technical skills and practices built on them as well as to the capacity to choose and appropriate technologies for personal goals and self-expression. Academic and learning capabilities are seen as more consistent, but also as more slowly changing in response to the networked technologies that have transformed professional practices. Information and media capabilities, in turn, are seen in the intersection of the two previous areas, and they involve the forms, both technological and cultural, in which academic meaning is communicated. According to the model, the development progresses from access and awareness, through skills and practices, to the level of identity and attributes. At that topmost level, students are able to create learning environments suited for their needs and preferences, plan their learning journey, use ICT to "access opportunity, showcase achievements and reflect on the outcomes", design original and meaningful projects as well as be critical users of digital technologies, resources and environments (Beetham \& Sharpe 2010). Complemented with the need for managing learning across sites and environments, and a deep understanding of the cultural aspects of networks, the model adequately sums up the skills needed for building a PLE and using it for learning. Consequently, using PLE building as a starting point might provide the students with the opportunity to learn these literacies in a meaningful way.

Selwyn (2010: 67) argues that educators need to address "educational technology as a profoundly social, cultural and political concern". The challenge of the course design presented in this article was twofold: first, to create a course 
design that would help the students in understanding, building and using their PLEs for the purpose of supporting their professional development; and second, to accomplish this in a manner that would itself reflect the pedagogical ideals of participatory, personalised and networked learning and distributed expertise associated with the PLE.

\section{The course design}

\subsection{Design principles}

The overall goal of the course was to equip the learners with the skills and competencies needed to create their own PLEs that would enable them to tap the networks and resources online for learning purposes, and to understand and seize the multiple affordances of technology and the internet in their professional and personal lives. The framework of PLE/N (see Figure 1 above in section 3) translated to the learning goals of the course as follows

- Personal: developing an understanding of one's own strengths and areas of development; setting larger professional and personal goals.

- Learning: setting short-term goals for the course; directing one's learning; grasping the affordances for learning on the internet.

- Environment: understanding one's PLE; seeing beyond it (how it can be developed, what the possibilities for developing it are, how to deal with the constant change); understanding the technologies and their functions.

- Network: understanding the principles of networked learning, understanding the cultural and communicational practices on the web.

Accordingly, the core goals for the course, as stated in the course syllabus, were set as follows: 
"After the course the students will understand their personal learning (and communication) environments and be able to develop them according to their needs; understand discursive and communicative practices of various networks and environments; be aware of their personal strengths and expertise and know how to communicate them on the internet; be able to plan their learning and professional development; know how to use digital resources and networks for their own learning in the future".

These general goals served as a starting point for the preliminary design of the course structure and content. In addition, to ensure the implementation of learner-centred pedagogy, the researcher-teachers created a set of principles for the learning culture on the course. Co-design was applied as a form of increasing student engagement and empowerment, and it was also seen as a means for being able to meet the diverse needs of the students. To achieve this and to encourage participation and interaction, students should be encouraged to take initiative, discuss and participate actively, and teachers should ensure that the hierarchy on the course is low and that they are perceived as learners themselves.

Merging the boundaries between informal and formal learning, learning as happening everywhere (serendipity) was seen as an important factor, and meaningfulness and real-life relevance were sought by closely intertwining the learning with students' personal projects. The principles of "backward design" (Wiggins 1998, in Fink 2003) were applied in how the design process and goal-setting for the course began from the desired long-term outcomes of the course, that is, from how it was envisioned that the course participants would be using the internet for their learning long after the course ended. The next step was designing the structure, contents and assignments. On top of these considerations, and as an ideological premise, the course principles should be made transparent and spelled out to the students, from the learning culture and students' responsibility for their learning to expectations of active participation and the co-design principle. 


\subsection{Participants, timeframe and contents}

The experiment was organised as a pop-up course at the Language Centre. It was an elective communication studies course available to all students irrespective of their faculty or stage of studies. There were only a few weeks from the announcement of the course to its opening for enrolment. The ideal group size for the experiment was considered to be 12, with a maximum of 18 students. This is a relatively small number of students, but for experimenting with the pedagogical ideas, working modes and methods it was considered to be optimal. Students could earn only 2 ECTS credits for the course, an amount that was not in proportion to the ideal workload for meeting the course objectives but that was sufficient to cover the minimum workload. However, the small number of credits had an effect on the course's official rate of student retention, as is explained later in section 5 .

One of the core questions in designing the course was how to have a design that would not detract from meeting the learning goals but which would provide a sense of organisation and structure and still allow for student participation in its design, personalised learning goals and working modes. To explore this, the designers started with something that might be called a best guess of the goals, contents and timeframe. They also realised that it would be important to spell out the culture of learning involved in the PLE as an educational ideology. That the course syllabus was considered to be a guess is important, and it means that the teacher should be flexible with contents. The course design was set to be open in order to incorporate principles of co-design, dialogue and learner engagement, all of which were seen as premises for student-centred design and learning about PLEs. For more about the co-design principle and its impact, see section 5 .

The face-to-face meetings were set to take place over four consecutive weeks. The following month was set for working on the personal projects, after which the projects were presented in class. Figure 2 presents the final timeframe of the course and the main contents of the class meetings. 
Figure 2. Course timeframe and contents

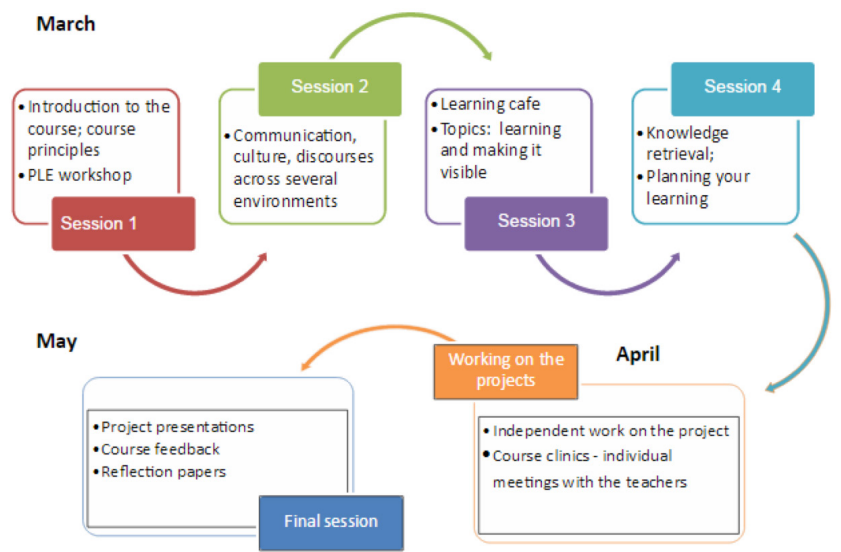

The course had a strong communicative and cultural focus, because this was also the gap identified in the ICT education of the students.

University's IT services offer courses on basic ICT skills, the university library organises courses on information retrieval and databases, and university students are at least assumed to have acquired the skills needed for critical thinking, lifelong learning and the evaluation of information. The design of the course thus filled a gap in the education of students in the skills they need for full professional lives in the digital world. In line with Beetham and Sharpe's (2010) digital literacies development framework, the course was targeted at the level of attributes/identities and practices (ways of thinking and acting), which would be best learned through project work tied closely to a student's personal development goals, and through the encouragement of participatory, networked and individual learning, respectively.

\subsection{Modes of work and assignments}

Technological skills (the skills and access levels in Beetham \& Sharpe 2010 framework) were not taught on the course as such. The learners were to build their PLEs using the platforms and environments of their choice. The possible 
need for support was fulfilled through clinics which the students were encouraged to attend individually with their questions and problems of any level. As an additional goal stemming from the core ideology of PLEs, clear connections were needed between the recreational use of digital media and its capacity for developing and performing professional and academic identities. The core of the course was the individual project of building some aspect of one's PLE on the internet for a specific purpose, and the assignments were designed and structured to support this specific goal throughout the course. Furthermore, the assignments were designed to familiarise the students with the digital networks central to their professional development, and at the same time the practices and modes of communication on several platforms and environments were analysed. The individual work was then discussed together in class and in the online environment. The online environment Yammer was used to support the sense of the course as a continuum, because it served as a place to meet and be present between the course meetings and during the individual work. The assignments were designed in a way that they both prepared for the forthcoming class meeting and continued the work on a specific theme afterwards in the online environment.

\section{The student perspective}

\subsection{Student retention}

In spite of the short enrolment time, 16 students from four faculties enrolled, and 14 answered the pre-course questionnaire. Twelve were present for the first two class meetings, after which one student left the course with the explanation that other tasks were taking so much time that she would not have the time for the course. Another student simply stopped attending. Her fellow student reported that she had explained that the course did not offer what she was expecting. The remaining 10 students participated actively in the course, both in class and online, and the quality of the student assignments and work was high. However, only seven students finished their personal project and received credit for the course. The three who attended the course but did not finish their 
project, however, all showed commitment to the course group and to the learning content. The staff member who participated in the in-class sessions later used the ideas and concepts from the course in his own work. The two first-year students announced that they did not particularly need the credits and did not have time for the project at that moment, but announced their willingness to complete the self-reflection assignment for the research, and one of them contacted the teachers a couple of months later to introduce the blog project he had started on collecting people's dreams about their future. The student's project was later expanded to an exposition and it received external funding.

The teachers concluded that the student behaviour and the observations on the course retention tell three things about the effects of tying learning and content to a learner's own identity-building and personal goals and of creating a learning community that also involves the teachers. One is that this seems to increase the commitment to the group and to the purpose of supporting the personal goals of its individual members. The students were willing to contribute to the teachers' research project even when they were not rewarded with credits. Another conclusion is that the significance and urgency of the larger goals beyond the course had a direct impact on the course outcomes. The closer the students were to their graduation or the more pressing their needs for seeking employment were, the more eager they were to finish their project. Finally, these two conclusions build into a question on the relationship between internal and external motivation in formal education. The two credits granted for the course were not important to the students as such, and did not encourage them to finish their projects when they did not feel that it was timely regarding their stage of studies. However, the learning community and course contents seemed to provide sufficient motivation for most of these students to actively participate in all of the classes.

\subsection{Enactment of co-design}

The analysis of field notes and actualised course practices and activities reveals that engaging the students in the design of the course took shape in several direct and indirect ways. 
Upon enrolment the students were asked to fill in a questionnaire that consisted of open-ended questions on the use of the internet and also on the students' expectations of the course. The answers to these questions were used to map the students' needs and helped to fine-tune the first design of the course.

In class the teachers aimed at creating a dialogue with the learners. The students were encouraged to ask questions, interrupt and participate actively. This approach also had perceivable effects and meant that occasionally the topics designed for class were not covered to the extent that was originally planned. From teachers, this requires an internalised belief that dialogue and interaction produce better learning outcomes and help to focus the course contents according to the learners' needs. This dialogue, ultimately, is more valuable than any planned contents. In addition, confidence in one's expertise and willingness to admit its limits are needed, and the answers to students' questions can often be found within the learning community in class or through participants' personal learning networks. Students also had an impact on the methods used in class. The third of the four in-class sessions was organised in the form of a group discussion and utilised the learning café method, which was not in the original course design but was requested by students.

The Yammer online environment was used when planning for the next in-class session. The teachers introduced the main topic of the session a few days earlier and asked the students for ideas, questions and particular sub-topics that they would want to have discussed in class. In addition, the online environment provided possibilities for expanding learning and discussing topics that were of interest to the students, sharing their work and creating interaction in the group. In addition, students were encouraged to familiarise themselves with the learning networks, platforms and environments they found to be of interest.

\subsection{Personalised learning on the course}

The choice of the shared online environment Yammer was initiated by the teachers as one option among others, such as Facebook and Twitter, but negotiated with the group during the first meeting. However, the students designed their own 
learning environments, tools and networks for the course as they worked on the assignments that encouraged them to familiarise themselves with the networks and people of interest on the internet. This meant that the social networks, platforms and connections were explicitly also part of the course's learning environment, and selected and designed by the students themselves.

The central form of directing the learning during the course was the personal project. Creating a course in which students design and build projects, in this case their PLEs, cannot be considered an innovative practice because it has been customary in many fields of study and domains of learning. However, this type of a project is almost a prerequisite for meeting the general goals set for the course. The project provided the learners with a chance to approach the use of the internet for learning and communication from an individually meaningful perspective and to pursue their learning goals and seek assistance and guidance in forms that best suit their needs. The various interests and focuses of the students also nurtured distribution of information in class, which supported the social learning processes as well.

To support the personal learning goals and project work, the students had the possibility to meet the teachers privately and to seek assistance on any topic they felt they needed help with. Because the meetings were voluntary, only half of the students booked a session with the teachers. At the time of the clinics, 10 students were still enrolled on the course, with an equal number of males and females. The teachers were unsure of whether it was a question of gender, but all of the students that came to the personal meetings were female. The topics addressed varied from practical help with environments such as LinkedIn and Blogger to more general and even theoretical discussion on using the internet for professional development and on cultural and discursive practices in the social networks.

\subsection{Reflections of personal learning and course culture}

During the presentation of the course projects, discussion on the way the course was designed emerged. One student expressed having experienced frustration at 
the beginning of the course because of the learner-centred pedagogical approach, a feeling that the rest of group seemed to mainly share:

"After the first meeting I was frustrated because you sort of got a lot and yet nothing out of it. Maybe after a while, as the course proceeded, you started to like the idea of the course and notice that it is useful. What was frustrating was that you knew that you had to find it yourself from there, that it is not served to you on a plate" (Mary, at the final course meeting).

In general, however, the approach was greeted positively, but regarding the rate of students quitting the course after the first session, this may be an issue that should be addressed. Especially the students that reported having fears and feeling incompetent in digital environments appreciated the open discussion.

"When I came back to study I thought that what I need is discussing things but you don't have the time for that at lectures and the lecturers put on a little pressure. But here we have had the time to discuss freely and say that 'I don't get it' and get insights from others into that issue" (Miriam, discussion at the final course meeting).

"I agree... There are others, that I am not the only one who thinks 'Hey, how do I do this, can I press this button?' In this sense it has been really nice and I have learned a lot" (Eva, in response to Miriam at the final course meeting).

The extent and especially the depth to which the students engaged in their development process varied greatly, as can be inferred from the analysis of the reflections at the end of the course. Around half of the students, in their final presentations and their reflective papers, stated mainly that they had had new ideas or learned about new tools. Technology and the PLE were seen as a set of instruments. However, these students also reported on the need to reflect upon one's expertise in another way: 
"When it comes to this course, forcing myself to think about and evaluate my professional expertise and to put it in words has been as important as creating a tool that helps me in job-hunting" (Miriam, project presentation at the final course meeting).

The other half of the students reported various changes, revelations or transformations related to themselves, their identity and future goals. These students had also shown more interest in the levels of culture and practice in social networks, and tended to take their learning on this course to a deep level. For example, Nina, a PhD student, reported how her project had brought her earlier thoughts on entrepreneurship to the surface, and how this, in turn, had brought a whole new meaning to the learning during the course:

"So this brought a whole new meaning to this activity (in the social networks). That I am not joining Twitter or creating a blog just for the sake of having done that, but it has a point and may help me in telling what I can do and in finding employment" (Nina, project presentation at the final course meeting).

John, a master's degree student, had thorough plans for his future and for the project, and at the beginning of the course he already had a good knowledge of the internet and social networks. He designed his PLE in a systematic way to serve his well-defined professional goals. However, the dialogue within the group also seemed to serve him, but in a different way than it did the others:

"In short, the consequences have been serendipitous, huge and very positive. I have gathered ideas and insights on this course and others during this spring. Although I often felt that the issue in focus was not relevant to me, some sidetrack or subordinate clause blew my mind. On this course this happened almost on every session, so I got exactly what was promised: insights. As a consequence my master's thesis developed towards a direction that when I had a work interview on Monday, on Tuesday we shook hands and agreed that I will start my new job next Monday" (John, reflection paper). 
By aligning the student feedback with information they provided upon enrolment and their personal goals for the project (an assignment at the beginning of the course), it can be concluded that what students learned from the course varied according to the stage of the studies they were at, their experience and attitudes toward ICT, and the goals they currently found meaningful at present. In sum, based on the feedback, reflections and observations, the PLE project allowed for personalised learning paths that meant, on one hand, that what the students reported to have learned varied a great deal (on the Beetham \& Sharpe 2010 framework from the awareness and access stages to practices and identities), but on the other, it may have increased both the meaningfulness and depth of learning. The low hierarchy and the positioning of teachers as learners themselves received direct compliments from the students. Based on the student reports and on a few newspaper articles published about the course participants, the course appeared to provide meaningful, in-depth experiences, and perhaps even to initiate transformations beyond the course scope.

\section{Conclusions}

Although this study does not offer a conclusive answer to the complex question of how digital literacies for personal professional learning are learned, it does offer insight into the pedagogical choices that may support a student's journey as a digital learner toward competences and skills that are needed in the networked society. It also sheds light on the multiple transformations that take effect in students' thinking and professional development. The question of how these complex and intertwined competences can be taught is perhaps not relevant on the level of individual skills. The more relevant question, then, is how to promote the personal learning process of students who have diverse backgrounds, experiences and attitudes as well as varying needs for support, goals for development and stages of studies. The dialogue on the course seems to enable this, at least to a certain degree, and point the learners towards pursuing their goals and developing their skills and knowledge further, according to their needs. In addition, modelling the course culture more after an affinity space (Gee 2007) than after a community of practice (Lave \& Wenger 1991) 
may be a potential solution that allows for various levels of participation and engagement from the students.

However, the pedagogies of dialogical, networked and personal learning are different from the prevalent pedagogical settings in formal education. Spelling out the rules and expectations for students may be a starting point, but without true opportunities for asking questions, expressing insecurities and directing the discussion towards areas of interest to the students, it may not be enough. From teachers, this approach demands willingness to release control and power, letting go of the planning mentality, and adopting the position of a co-learner. The principle of co-design was implemented with relatively simple means. The way the course environment was used created possibilities for sharing and networked learning, but also provided the course members with an arena for participation in the course design. This indicates that creating a learning culture that offers true possibilities for personal development and deep learning does not require specific tools or methods, but presumes a learning culture that encourages participation and offers possibilities for individuality and personalisation. In other words, organising the teaching and learning in alignment with the values that are inherent in the participatory, networked culture and in the studentcentred idea of learning.

\section{References}

Attwell, G. 2007. Personal learning environments - the future of eLearning? eLearning papers, 2 (1). Retrieved from http://www.openeducationeuropa.eu/en/article/PersonalLearning-Environments---the-future-of-eLearning\%3F?paper=57211

Barab, S. \& Squire, K. 2004. Design-Based Research: putting a stake in the ground. The Journal of the Learning Sciences, 13 (1), 1-14. doi:10.1207/s15327809j1s1301_1

Beetham, H. \& Sharpe, R. 2010. Digital literacy framework. JISC - The Design Studio. Retrieved from http://jiscdesignstudio.pbworks.com/w/page/46740204/Digital\%20 literacy $\% 20$ framework

Downes, S. 2007. Learning networks in practice. Emerging technologies for learning, 2. Retrieved from http://www.downes.ca/files/Learning_Networks_In_Practice.pdf 
Drexler, W. 2010. The networked student model for construction of personal learning environments: Balancing teacher control and student autonomy. Australasian Journal of Educational Technology, 26 (3), 369-385.

Fink, L. D. 2003. Creating significant learning experiences: an integrative approach to designing college courses. San Francisco: Jossey-Bass. 63-64.

Gee, J. P. 2007. Affinity spaces: from age of mythology to today's schools. Good Video Games and Good Learning: Collected Essays on Video Games, Learning and Literacy. Peter Lang: New York, 87-103.

Guth, S. 2009. Personal learning environments for language learning. In S. Thomas (ed.), Handbook of research on Web 2.0 and Second Language Learning. London: IGI Global. doi:10.4018/978-1-60566-190-2.ch024

Jenkins, H., Purushotma, R., Clinton, K., Weigel, M. \& Robison, A. J. 2005. Confronting the challenges of participatory culture: media education for the 21st Century. Building the field of digital media and learning. Chicago: MacArthur Foundation. Retrieved from http://www.newmedialiteracies.org/wp-content/uploads/pdfs/NMLWhitePaper.pdf

Joseph, D. 2004. The practice of Design-Based Research: uncovering the interplay between design, research, and the real-world context. Educational Psychologist, 39 (4), 235-242. doi:10.1207/s15326985ep3904_5

Juntunen, M. \& Laakkonen, I. 2014. PLE - tapa oppia [PLE - a way to learn]. In P. Häkkinen \& J. Viteli (eds.), Pilvilinnoja ja palomuureja - Tulevaisuuden oppimisen ja työnteon tilat. F-SHAPE-projektin satoa [Clouds and firewalls. Findings from the F-SHAPE project]. Jyväskylä: Finnish Institute for Educational Research, 59-81. Retrieved from https://ktl. jyu.fi/julkaisut/julkaisuluettelo/julkaisut/2014/D109.pdf

Laakkonen, I. 2011. Personal learning environments in higher education language courses: an informal and learner-centred approach. In S. Thouësny \& L. Bradley (eds.), Second language teaching and learning with technology: views of emergent researchers. Dublin: Research-publishing.net, 9-28. doi:10.14705/rpnet.2011.000004

Laakkonen, I. \& Taalas, P. 2015. Towards new cultures of learning: personal learning environments as a developmental perspective for improving higher education language courses. Language Learning in Higher Education, 5 (1), 223-241. doi:10.1515/ cercles-2015-0011

Lankshear, C. \& Knobel, M. 2007. Sampling "the new" in new literacies. In M. Knobel, C. Lankshear, C. Bigum, \& M. Peters (eds.), A New Literacies Sampler. New York: Peter Lang, 1-24. 
Lave, J. \& Wenger, E. 1991. Situated learning: legitimate peripheral participation. Cambridge: Cambridge University Press. doi:10.1017/CBO9780511815355

Littlejohn, A., Beetham, H. \& McGill, L. 2012. Learning at the digital frontier: a review of digital literacies in theory and in practice. Journal of Computer Assisted Learning, 28, $547-556$.

Ludvigsen, S., Lund, A., Rasmussen, I. \& Säljö, R. 2011. Learning across sites. Learning across sites: new tools, infrastructures and practices. New York: Routledge.

Selwyn, N. 2010. Looking beyond learning: notes towards the critical study of educational technology. Journal of Computer Assisted Learning, 26 (1), 65-73.

Siemens, G. 2005. Connectivism: a learning theory for the digital age. International Journal of Instructional Technology and Distance Learning, 2 (1), 3-10.

Sykes, J., Ozkoz, A. \& Thorne, S. 2008. Web 2.0, synthetic immersive environments, and mobile resources for language education. CALICO Journal, 25 (3), 528-546.

Reinking, D. \& Bradley, B. A. 2007. On formative and design experiments: approaches to language and literacy research. New York: Teachers' College.

van Harmelen, M. 2008. Design trajectories: four experiments in PLE implementation. Interactive Learning Environments - Special Issue: Personal Learning Environments, 16 (1), 35-46. doi:10.1080/10494820701772686

Wiggins, G. 1998. Educative assessment: designing assessments to inform and improve student performance. San Francisco: Jossey Bass. 


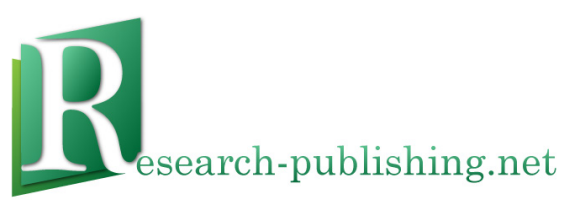

Published by Research-publishing.net, not-for-profit association Dublin, Ireland; Voillans, France, info@research-publishing.net

(C) 2015 by Research-publishing.net (collective work)

Each author retains their own copyright

Voices of pedagogical development - Expanding, enhancing and exploring higher education language learning Edited by Juha Jalkanen, Elina Jokinen, \& Peppi Taalas

Rights: All articles in this collection are published under the Attribution-NonCommercial -NoDerivatives 4.0 International (CC BY-NC-ND 4.0) licence. Under this licence, the contents are freely available online (as PDF files) for anybody to read, download, copy, and redistribute provided that the author(s), editorial team, and publisher are properly cited. Commercial use and derivative works are, however, not permitted.

\section{()ㅛ $\Theta \Theta$}

Disclaimer: Research-publishing.net does not take any responsibility for the content of the pages written by the authors of this book. The authors have recognised that the work described was not published before, or that it is not under consideration for publication elsewhere. While the information in this book are believed to be true and accurate on the date of its going to press, neither the editorial team, nor the publisher can accept any legal responsibility for any errors or omissions that may be made. The publisher makes no warranty, expressed or implied, with respect to the material contained herein. While Research-publishing.net is committed to publishing works of integrity, the words are the authors' alone.

Trademark notice: Product or corporate names may be trademarks or registered trademarks, and are used only for identification and explanation without intent to infringe.

Copyrighted material: Every effort has been made by the editorial team to trace copyright holders and to obtain their permission for the use of copyrighted material in this book. In the event of errors or omissions, please notify the publisher of any corrections that will need to be incorporated in future editions of this book.

Typeset by Research-publishing.net

Cover design by (C) Antti Myöhänen

ISBN13: 978-1-908416-25-4 (Paperback - Print on demand, black and white)

Print on demand technology is a high-quality, innovative and ecological printing method, with which the book is never 'out of stock' or 'out of print'.

ISBN13: 978-1-908416-26-1 (Ebook, PDF, colour)

ISBN13: 978-1-908416-27-8 (Ebook, EPUB, colour)

Legal deposit, Ireland: The National Library of Ireland, The Library of Trinity College, The Library of the University of Limerick, The Library of Dublin City University, The Library of NUI Cork, The Library of NUI Maynooth, The Library of University College Dublin, The Library of NUI Galway.

Legal deposit, United Kingdom: The British Library.

British Library Cataloguing-in-Publication Data.

A cataloguing record for this book is available from the British Library.

Legal deposit, France: Bibliothèque Nationale de France - Dépôt légal: septembre 2015. 